\title{
Surface Modification of Thin Polyion Complex Film with a High Specific Binding Affinity and Prevention of Non-specific Adsorption in Surface Plasmon Resonance Immunoassay
}

\author{
Ryoji Kurita, * Yoshiki Hirata, Soichi Yabuki, Dai Kato, \\ Yukari Sato, Fumio Mizutani, and Osamu Niwa
}

\author{
National Institute of Advanced Industrial Science and Technology (AIST) (1-1-1 Higashi, Tsukuba, Ibaraki 305-8566, \\ Japan)
}

Received August 19, 2005 ; Accepted November 11, 2005

\begin{abstract}
The non-labeled and direct immunoassay of cytokine on a thin polyion complex film of poly-L-lysine and poly-styrenesulfonate was studied using a surface plasmon resonance sensor. The suppression of non-specific protein adsorption was investigated by changing the blend ratio of poly-L-lysine and poly-styrenesulfonate. With our film, the protein adsorption fell to less than $10 \%$ of that of an unmodified surface when the poly-L-lysine to poly-styrenesulfonate ratio was 4:6. We also measured the kinetic rates between tumor necrosis factor- $\alpha$ and anti-tumor necrosis factor- $\alpha$ antibodies, which were immobilized on the film. The binding constant was calculated to be $1.5 \times 10^{8}\left(\mathrm{M}^{-1}\right)$, which satisfies the binding constant level for a monoclonal antibody modified on a commercially available surface.
\end{abstract}

Key Words : Polyion Complex Film, Surface Plasmon Resonance, Non-specific Adsorption, Immunoassay, TNF- $\alpha$

\section{Introduction}

Surface plasmon resonance (SPR) has been successfully incorporated into an immunosensor format for the simple, rapid, and non-labeled assay of various biochemical analytes. ${ }^{1-4)}$ However, its major disadvantages are its low sensitivity for small molecule detection and its low selectivity caused by non-specific adsorption. Thus, recent SPR research has focused on sensing surface functionalization with the goal of reducing the detection limit by improving biocompatibility.

With a view to obtaining a low detection limit, studies have been undertaken on the oriented immobilization of antibodies on the sensing surface by using a self-assembled monolayer. ${ }^{5}$, 6) However, some immobilized antibodies are unable to form stable layers because they are denatured to lose their specific activity compared with that of free antibodies.

The non-specific adsorption of biomolecules, especially protein fouling, often reduces the sensing capability in real sample measurements. ${ }^{7}$ Since an SPR sensor simply responds to refractive index changes on the sensing surface, it is impossible to distinguish whether the SPR angle shift is caused by specific or non-specific adsorption. Various modifications of the film on the sensing surface have been used to suppress the protein fouling. ${ }^{8,9)}$ Thin polymer films of dextran, poly (ethylene glycol), hydroxyl starch and poly (vinyl alcohol) have been employed to form a non protein fouling surface. ${ }^{10-13)}$ For a highly sensitive and selective SPR immunosensor, it is more convenient if the membrane on the sensing surface has both a less non-specific adsorption property and functional groups for immobilizing the antibodies without losing their specific binding activity.
In this paper, we first report the surface modification of an SPR immunosensor with a thin polyion complex film consisting of poly-L-lysine and poly-styrenesulfonate. We studied the effects of the non-specific adsorption of bovine serum albumin on the sensing surface using SPR and AFM while varying the polymer blend ratio. We also measured the kinetics rate between tumor necrosis factor- $\alpha(\mathrm{TNF}-\alpha)$ and anti-tumor necrosis factor- $\alpha$ (anti TNF- $\alpha$ ) antibodies, which were immobilized on the polyion complex film.

\section{Experimental}

2.1 Preparation of polyion complex film for SPR immunoassay

Thin titanium was deposited on glass plates by using an RF sputtering machine, and gold film was then formed without breaking the vacuum. ${ }^{14)}$ The total thickness of the gold and titanium film was $50 \pm 2 \mathrm{~nm}$. We then sealed the glass plate using an adhesive sheet with a $3 \mathrm{~mm}$ diameter hole. We placed aqueous solutions of poly-L-lysine (average M.W. 80000, Sigma) and poly-styrenesulfonate (average M.W. 70000, Aldrich) successively on the gold film on the plate, and allowed the plate to dry for $4 \mathrm{hrs}$ at room temperature. ${ }^{15)}$ The concentrations of poly-L-lysine and poly-styrenesulfonate were varied from $2.5 \mathrm{nM}$ to $25 \mathrm{mM}$ as a monomer unit to obtain films with different thicknesses. We also changed the blend ratio of the polyion complex film by changing the amounts of both solutions from 7:3 to 1:9. The total volume of solution loaded on each plate was $10 \mu \mathrm{L}(1.4$ $\mu \mathrm{L} / \mathrm{mm}^{2}$ ).

When we examined the binding kinetics of immobilized anti TNF- $\alpha$ (Sigma) on the polyion complex film, we 
used the common carbodiimide coupling reaction provided by N-hydroxysuccinimide (NHS, Pierce) and N-ethylN'-(3-dimethyl aminopropyl) carbodiimide hydrochloride (EDC, Pierce) system as follows. ${ }^{16)}$ We immersed the polyion complex film in $10 \mathrm{mM}$ phosphate buffer containing both $0.4 \mathrm{mg} / \mathrm{mL}$ EDC and $1.1 \mathrm{mg} / \mathrm{mL}$ NHS for 15 min at room temperature. We then added anti TNF- $\alpha$ to the buffer to realize a final concentration of $0.1 \mathrm{mg} / \mathrm{mL}$, and incubated it for $2 \mathrm{hrs}$ at room temperature.

\subsection{Measurements}

Before undertaking the measurements, we peeled the adhesive sheet from the plate, and attached the plate to a poly-dimethylsiloxane (PDMS) chip with a thin layer flow channel that was $2 \mathrm{~mm}$ wide and $20 \mu \mathrm{m}$ deep. $\left.{ }^{17}\right) \mathrm{We}$ connected an inlet and an outlet tube to the PDMS chip. We also connected the other end of the outlet tube to a syringe and installed the syringe in a syringe pump. A phosphate buffer solution (pH 7.0, Nakalai) was introduced onto the plate at a flow rate of $2 \mu \mathrm{L} / \mathrm{min}$ by using suction. We obtained the minimum reflection angle of the SPR curve $(\theta S P R)$ using Handy-SPR equipment (NTTAT), which has a Kretschmann configuration. Index matching oil $(\mathrm{n}=1.510$, Cargille Laboratories Inc) was used to obtain optical contact between the gold plate and the prism.

\section{Results and Discussion}

First, we obtained polyion complex films with various thicknesses, which we achieved by changing the poly-Llysine and poly-styrenesulfonate concentrations. $\theta S P R$ was around 67.5 degrees, and a narrow SPR curve was observed when the each concentrations of poly-L-lysine and poly-styrenesulfonate were same and less than 2.5 $\mu \mathrm{M}$ as a monomer unit, respectively. $\theta S P R$ and the shape of the SPR curve were almost same as that of unmodified gold film. However, the $\theta S P R$ value increased and the SPR curve broadened when the concentrations were above $2.5 \mu \mathrm{M}$ as a monomer unit. We decided on a film formation concentration of $2.5 \mu \mathrm{M}$ as a monomer unit, respectively, because a thin polymer layer is advantageous in terms of highly sensitive measurement because the intensity of the evanescent field decreases with distance from the gold surface. The film thickness was around $4.5 \mathrm{~nm}$ based on AFM observation. This polymer was much thinner than previously reported modified polymers other than those where the selfassembly technique was used. Though polyion complex deposited when we mixed poly-L-lysine and poly-styrenesulfonate solutions, the gold surface was covered with the film and flat hill-like structures were observed as shown in Fig 1.

Figure 2 (a) (b) (c) shows the typical change in $\theta S P R$ when $1 \mathrm{mg} / \mathrm{mL}$ bovine serum albumin (BSA) solution was introduced for $5 \mathrm{~min}$ onto a plate with/without the polyion complex film. When we injected the BSA solution onto a gold film without polyion complex film, the $\theta S P R$ increased rapidly and reached a steady state. The $\theta S P R$ decreased slightly when the phosphate buffer solution was introduced again because the protein fouling caused by low affinity was removed from the surface.

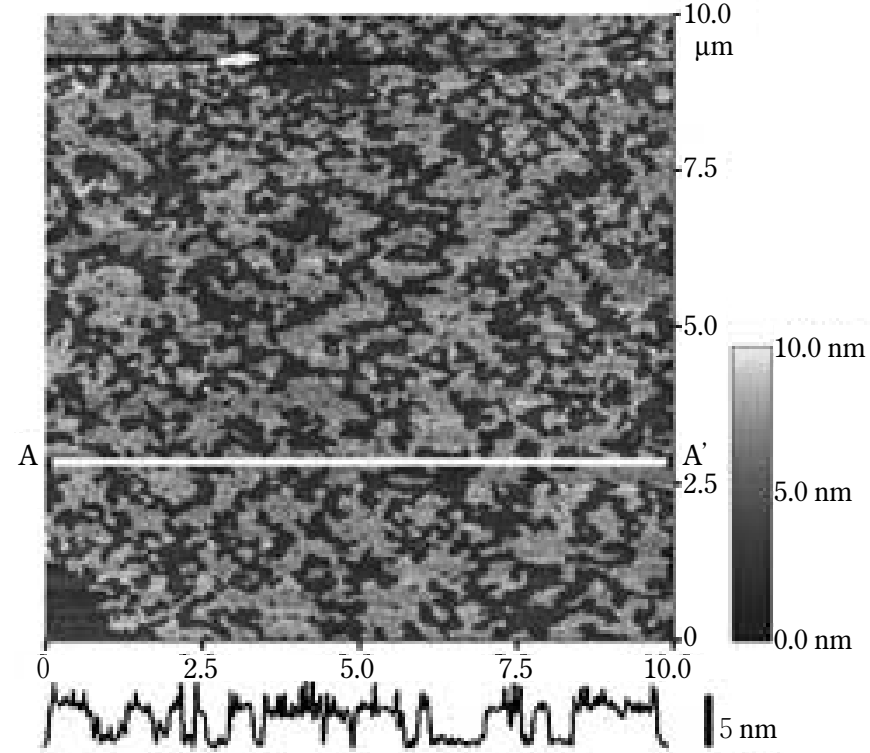

Fig. 1 AFM image $(10 \mu \mathrm{m} \times 10 \mu \mathrm{m})$ of a gold surface modified with thin polyion complex film. The height profile across A-A' is given beneath the AFM image. The film was formed by mixing the poly-L-lysine to poly-styrenesulfonate with ratio of $4: 6$.

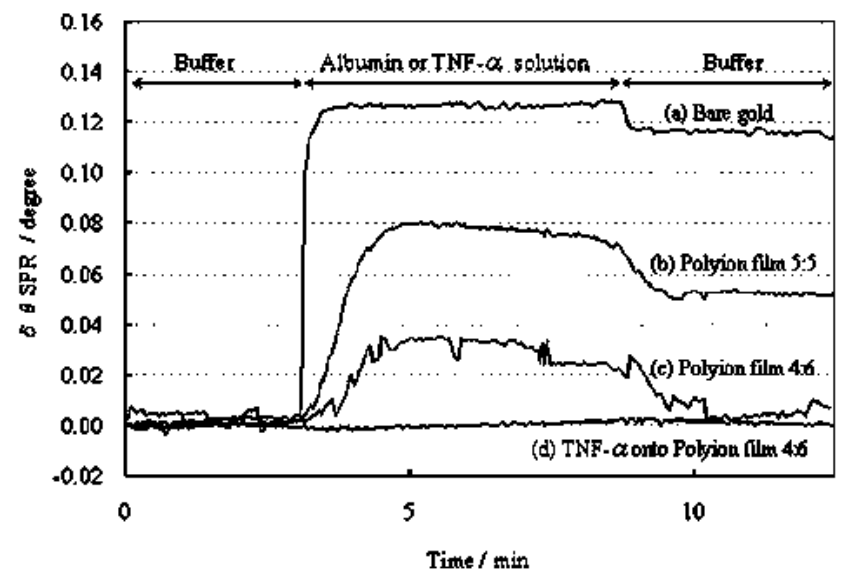

Fig. 2 (a) (b) (c) SPR sensorgram for $1 \mathrm{mg} / \mathrm{mL}$ BSA solution introduced onto the modified/unmodified sensing surface at a flow rate of $2 \mu \mathrm{L} / \mathrm{min}$. ; (d) SPR sensorgram for $100 \mathrm{ng} / \mathrm{mL}$ TNF- $\alpha$ solution onto the 4:6 polyion complex film.

The $\theta S P R$ shift value obtained after the second phosphate buffer injection showed that the $\theta S P R$ shift caused by BSA adsorption was $114 \times 10^{-3}$ degrees. This means that $1.14 \mathrm{ng} / \mathrm{mm}^{2} \mathrm{BSA}$ was adsorbed on the gold surface because a $\theta S P R$ shift of 1 degree is reported to correspond to $10 \mathrm{ng} / \mathrm{mm}^{2}$ protein adsorption. ${ }^{18,19)}$ This amount of adsorbed BSA is similar to that of a previous report. ${ }^{20)}$

On the other hand, we obtained a slower $\theta S P R$ increase when the gold surface was modified with polyion complex film. The $\theta S P R$ shift values were also lower than that of unmodified gold plate. They were 
$52 \times 10^{-3}$ and $4 \times 10^{-3}$ degrees when the polyion complex film was formed by mixing the poly-L-lysine to polystyrenesulfonate with ratios of 5:5 and 4:6, respectively. A slower and smaller SPR sensorgram generally means a low association rate constant, and this indicates that the polyion complex film is effective in suppressing protein fouling. We also examined the non-specific adsorption of a typical cytokine, TNF- $\alpha$. The concentration of TNF- $\alpha$ in human blood is reported around $10 \mathrm{pg} / \mathrm{mL} \sim$ $10 \mathrm{ng} / \mathrm{mL}$. We introduced $100 \mathrm{ng} / \mathrm{mL}$ TNF- $\alpha$ solution onto the 4:6 polyion complex film, and confirmed that no $\theta S P R$ increase was observed as shown trace (d) in Fig 2.

Figure 3 shows the variation in the $\theta S P R$ shift for 1 $\mathrm{mg} / \mathrm{mL}$ BSA solution when we varied the blend ratio of the polyion complexes used for film formation. The protein fouling was well suppressed when the poly-L-lysine to poly-styrenesulfonate blend ratio was between 5:5 and 3:7. The $\theta S P R$ shift value was almost same as that of an unmodified gold surface when the mixing ratio was extremely different. Non-specific adsorption was prevented when the blend ratio was 4:6. We consider that anionic polymer is formed when the mixture is poly-styrenesulfonate rich. BSA is rejected by electrostatic repulsion because the isoelectric point of BSA is 4.7.

The average $\theta S P R$ shift value was $9 \times 10^{-3}$ degrees when the blend ratio was $4: 6$, and this corresponds to about $0.09 \mathrm{ng} / \mathrm{mm}^{2}$ of adsorbed proteins. We achieved a non-specific adsorption that was less than $10 \%$ that of bare gold film. Recently, Uchida et al compared the nonspecific adsorption of $1 \mathrm{mg} / \mathrm{mL}$ BSA using a commercially available carboxymethylated dextran surface and synthesized poly (ethylene glycol) by employing an SPR measurement. ${ }^{20)}$ They reported that the amounts of BSA adsorbed on a carboxymethylated dextran surface and poly (ethylene glycol) are 0.059 and $0.024 \mathrm{ng} / \mathrm{mm}^{2}$, respectively. We were able to obtain almost the same result simply by mixing two polymers in a short time, although the amount of adsorbed BSA reported in this paper is slightly larger than that reported by Uchida et $a l$. This difference may be because the gold surface is not completely covered with film, as clearly revealed by the AFM observations. Furthermore, although it is difficult to modify an antibody on poly (ethylene glycol) film

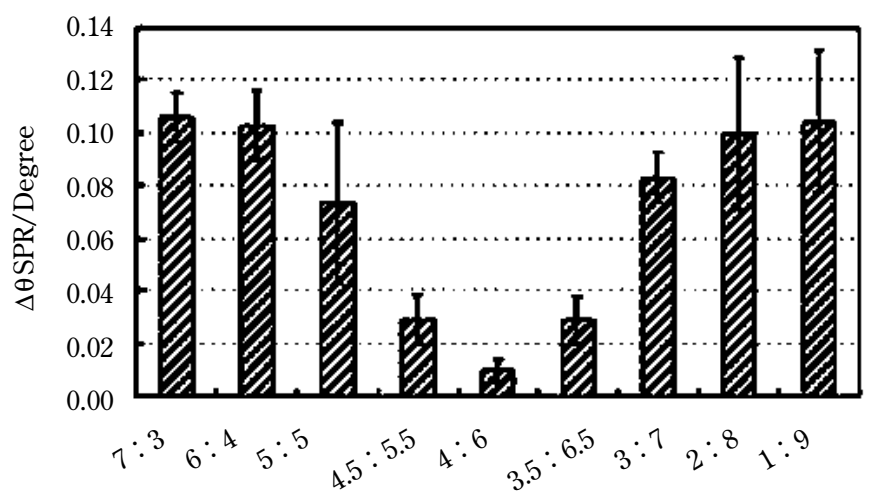

Fig. 3 Variation in the non-specific adsorption when the poly-L-lysine to poly-styrenesulfonate blend ratio is varied. because there are no functional groups such amino or carboxyl groups, which are commonly used to immobilize antibodies or antigens, our polyion complex film has many amino groups.

We examined the binding kinetics of an antibody immobilized on our polyion complex film because it is known that antibodies immobilized on a solid surface often lose their specific activity. We calculated the binding kinetics on the basis of a report by Karlsson et al ${ }^{21)}$ with a 1:1 Langmuir binding model. The association rate constant $(K a)$ and dissociation constant $(K d)$ were estimated to be $3.7 \times 10^{4}\left(\mathrm{M}^{-1} \mathrm{sec}^{-1}\right)$ and $2.5 \times 10^{-4}\left(\mathrm{sec}^{-1}\right)$, respectively. From the quotient of the rate constant $K a / K d$, the binding constant was $1.5 \times 10^{8}\left(\mathrm{M}^{-1}\right)$. We obtained a relatively higher binding constant given that the typical binding constant of monoclonal antibody modified on a commercially available surface is around $10^{6}$ to $\left.10^{8} .{ }^{21}, 22\right) \quad$ This result indicates that we are able to modify antibodies without losing a specific affinity. This could be due to the high biocompatibility of our polyion complex film without protein denaturation.

\section{Conclusion}

This paper describes the modification of a sensing metal surface in SPR immunoassay with thin polyion complex film. The film shows both the suppression of non-specific adsorption and the high specific affinity of an immobilized antibody. Though we describe only TNF$\alpha$ monitoring, the film is applicable to various biomolecules for non-labeled direct immunoassay by changing the antibodies.

\section{References}

1) V. Kanda, J. K. Kariuki, D. J. Harrison, and M. T. McDermott, Anal. Chem., 76, 7257 (2004).

2) B. Fitzpatrick and R. O'Kennedy, J. Immuno. Methods, 291, 11 (2004).

3) T. Akimoto, K. Ikebukuro, and I. Karube, Biosens. Bioelectron., 18, 1447 (2003).

4) K. V. Gobi, S. J. Kim, R. Harada, and N. Miura, Electrochemistry, 71, 430 (2003).

5) B. K. Oh, W. Lee, B. S. Chun, Y. M. Bae, W. H. Lee, and J. W. Choi, Colloids and Surfaces A, 257-258, 369 (2005).

6) T. Uda, K. Inoue, T. Nishimura, E. Hifumi, K. Shimizu, and N. Egashira, Electrochemistry, 69, 976 (2001).

7) R. Kurita, H. Tabei, Y. Iwasaki, K. Hayashi, K. Sunagawa, and O. Niwa, Biosens. Bioelectron., 20, 518 (2004).

8) V. Silin, H. Weetall, and D. J. Vanderah, J. Colloid Interface Sci., 185, 94 (1997).

9) M. Mrksich, G. B. Sigal, and G. M. Whitesides, Langmuir, 11, 4383 (1995).

10) D. A. Barrett, M. S. Hartshorne, M .A. Hussain, P. N. Shaw, and M. C. Davis, Anal. Chem., 73, 5232 (2001).

11) J. M. Brockman, A. G. Frutos, and R. M. Corn, J. Am. Chem. Soc., 121, 8044 (1999).

12) A. Akkoyun and U. Bilitewski, Biosens. Bioelectron., 17, 655 (2002).

13) S. Toyama, A. Shoji, Y. Yoshida, S. Yamauchi, and Y. Ikariyama, Sens. and Actuators B, 52, 65 (1998).

14) R. Kurita, H. Tabei, Z. Liu, T. Horiuchi, and O. Niwa, 
Sens. and Actuators B, 71, 82 (2000).

15) S. Yabuki, F. Mizutani, and Y. Hirata, Electrochemistry, 71, 408 (2003).

16) M. R. Lewis, A. Raubitschek, and J. E. Shively, Bioconjugate Chem., 5, 565 (1994).

17) D. C. Duffy, J. C. McDonald, O. J. A. Schueller, and G. M. Whitesides, Anal. Chem., 70, 4974 (1998).

18) L. G. Fagerstam, A. Frostellkarlsson, R. Karlsson, B. Persson, and I. Ronnberg, J. Chromatogr. 597, 397 (1992).
19) E. Stenberg, B. Persson, H. Roos, and C. Urbaniczky, J. Colloid Interface Sci., 143, 513 (1991).

20) K. Uchida, H. Otsuka, M. Kaneko, K. Kataoka, and Y. Nagasaki, Anal. Chem., 77, 1075 (2005).

21) R. Karlsson, A. Michaelsson, and L. Mattsson, J. Immuno. Meth., 145, 229 (1991).

22) F. Yang, X. Q. Cui, X. R. Yang, T. Chen, and J. Lu, Chem. J. Chin. Univ.-Chin., 23, 382 (2002). 